\title{
Epistemic injustice, children and mental illness
}

\author{
Edward Harcourt
}

Faculty of Philosophy, Humanities Division, University of Oxford, Oxford, UK

\section{Correspondence to}

Professor Edward Harcourt, Philosophy, University of Oxford Humanities Division, Oxford OX2 6GG, UK;

edward.harcourt@philosophy. ox.ac.uk

Received 16 February 2021

Accepted 9 June 2021

Published Online First

25 June 2021

\section{ABSTRACT}

The concept of epistemic (specifically testimonial) injustice is the latest philosophical tool with which to try to theorise what goes wrong when mental health service users are not listened to by clinicians, and what goes right when they are. Is the tool adequate to the task? It is argued that, to be applicable at all, the concept needs some adjustment so that being disbelieved as a result of prejudice is one of a family of alternative necessary conditions for its application, rather than a necessary condition all on its own. It is then argued that even once adjusted in this way, the concept does not fit well in the area where the biggest efforts have been made to apply it so far, namely the highly sensitive case of adult patients suffering from delusions. Indeed it does not serve the interests of service users struggling for recognition to try to apply it in this context, because there is so much more to being listened to than simply being believed. However, the concept is found to apply smoothly in many cases where the service users are children, for example, in relation to children's testimony on the efficacy of treatment. It is suggested that further research would demonstrate the usefulness of the concept in adult cases of a similar kind.

\section{INTRODUCTION}

In this paper, I argue that the experiences as health service users both of children and of people with mental health problems challenge some recent applications of the notion of epistemic, and specifically testimonial, injustice. I then propose some new ways forward.

There is evidence that being listened to is important both to mental health service users' satisfaction with services, and to the services' therapeutic efficacy. Independently, a particular form of epistemic injustice ${ }^{1}$ - testimonial injustice-has been found to have wide application in contexts where race and gender stereotypes operate in limiting, or inflating, a person's credibility. ${ }^{1-3}$ As if to put these two trends of thought together, the concept of epistemic and especially testimonial injustice is gaining ground in the philosophical literature on mental health and mental illness as the way to capture (some) service users' expressed dissatisfaction with mental health services. In this paper I explore the prospects for applying the concept of testimonial injustice to service users' encounters with mental health services by comparing these types of case both with the familiar race and gender applications and with the case of children who are ill (not always mentally ill). This investigation exposes to view some of the underexplored difficulties the mentally ill (including children) face in being listened to in clinical contexts, and helps us to refine our understanding of the concept of testimonial injustice and of its applications.

\section{Theorising not being listened to: is epistemic injustice the right tool?}

In describing their experiences, people who have used mental health services often say things like 'they listened (didn't listen) to me' and 'they treated me (didn't treat me) like a person'. When things go well between service users and clinicians or other mental health professionals, these expressions feature prominently among service users' accounts of why they go well, and the same goes mutatis mutandis when they go badly. Either way, 'being listened to', 'being treated like a person' and similar phrases are an important dimension along which to plot service users' sense of how valuable they find their encounters with mental health services.

This anecdotal impression is backed up in the literature. ${ }^{4}$ Service users describe bad relationships with psychiatrists as 'paternalistic and disrespectful'. The service users' own sense of what would be good for them was ignored, with service users seen primarily as objects of research ${ }^{5}$ rather than as human beings. Conversely, service users value psychiatrists who have 'the personal touch'; they wish to be 'treated as whole human beings', and 'acknowledged and respected'. '

Moreover these reports are not expressions merely of service users' likes and dislikes: the quality of the relationship with the clinician (or other mental health professional)—and 'being listened to', 'being respected', 'being treated as a human being' are presumably all part of that-is therapeutically valuable. ${ }^{7-12}$

However, expressions like 'being listened to' or 'being treated like a human being' are not theoretical descriptions of why clinical encounters go well or badly: they are just things people say. It's for philosophy to analyse what it is about a clinical relationship, or a one-off clinical encounter, that people point to when they use such expressions.

In search of theoretical tools to make sense of these expressions, it is attractive to turn to Miranda Fricker's book Epistemic Injustice. ${ }^{1}$ Being a knower-being someone who can acquire knowledge, and someone whom others can rely on as a source of knowledge-is important to social life. Just think how many of our everyday transactions involve our dependence on one another as acquirers of and sources of knowledge: asking someone the time, or for directions, or how much something costs. And because so many everyday transactions are like that, not being seen by others as a possible source of knowledge is a specific and important form of social exclusion. That is one reason why Fricker says epistemic injustice is about being 'wronged in one's capacity as a knower' (p20). ${ }^{1}$

I choose to focus on one of the two forms of epistemic injustice Fricker outlines, 'testimonial' injustice. On Fricker's account, to suffer testimonial 
injustice one must (1) suffer a 'credibility deficit', and (2) do so as a result of the 'ethical poison"1 (p22) of prejudice. For (1), one must be regarded not only as not credible, but as less credible than one deserves. Consider Alan, who volunteers a diagnosis of a friend's condition. Though Alan cannot remember a source for his view, the source is a medically authoritative poster he once read in a hospital waiting room. So he gets the diagnosis right-because he possesses knowledge. But Alan's friend does not believe Alan. Moreover, Alan is generally clueless on medical questions, so her disbelief is wholly reasonable, so Alan does not suffer a credibility deficit. Now consider another case: a local official dismisses Beth's representations against a parking fine based on her account of the circumstances. Her account is the expression of knowledge and-let's suppose-the official is familiar with representations similar to hers and generally believes them. So Beth is undeservedly disbelieved. But she is disbelieved simply because the official is in a bad mood: anyone's account would have been disbelieved on that occasion. Here, we have a credibility deficit, but no prejudice, so again on Fricker's view no testimonial injustice. Contrast the case where Charles, a black witness in court, is regarded as not credible, not because of the quality of his evidence but because of his skin colour (p23). ${ }^{1}$ Lack of medical training is a reasonable (though fallible) heuristic for lack of medical knowledge; skin colour is not any kind of heuristic for the kinds of epistemic capacity (eg, reliable memory, truthfulness) relevant to giving evidence in court. Prejudice is at work behind that credibility deficit, so Charles suffers testimonial injustice. Numerous similar examples of race-based and gender-based testimonial injustice spring to mind.

Women and racial minorities may not be the only social groups who have difficulty in getting themselves listened to, or who suffer from credibility deficits as a result of prejudice. People who experience mental health problems are the object of prejudice in a variety of (not just clinical) settings ${ }^{13}$ and, as explained, can feel they are not listened to by clinicians. Perhaps unsurprisingly, there is a growing literature which seeks to apply Fricker's notion of epistemic injustice to analyse what goes wrong (when it does) in encounters between service users and mental health services. ${ }^{314-19}$ Indeed Crichton et al appeal to the notion to analyse one of the ordinary-language expressions we started out with (being 'perceived as a person,15 (p69); Kurs and Grinshpoon do so with another ("not being listened to"16 (p336)). It is time to ask whether this growing literature is on the right track.

\section{Mental illness and compromised rationality: a preliminary challenge}

Consider this passage from Fricker:

[When someone is a victim of epistemic injustice and] knowledge and other rational input they have to offer are missed by others ... they suffer a sustained assault in respect of a defining human capacity, an essential attribute of personhood. ${ }^{1}$ (p59)

Fricker emphasises offering 'rational input', but the 'essential attribute of personhood' she has in mind is the 'ability to participate in the spread of knowledge by testimony and to enjoy the respect enshrined in ... proper relations of trust'. In a second passage, however, the link between rationality and humanity is further emphasised:

The capacity to give knowledge to others is one side of that manysided capacity so significant to human beings ... the capacity for reason. ... [O]ur rationality is what lends humanity its distinctive value. ... [I]nsult to someone in respect of a capacity essential to human value... adds a layer of harm of its own: [its social meaning is that] the subject is less than fully human. ${ }^{1}$ (p44)

The problem is that arguably some impairment of a person's rational powers is built in to the concept of mental illness. ${ }^{20} \mathrm{But}$ if every mental health service user is impaired with respect to their rationality, it might be thought to follow that they fail to meet the threshold - rationality-for being entitled to epistemic justice. If so, whatever people with mental health problems suffer at the hands of insensitive clinicians, it cannot be epistemic injustice. That would be a swift argument to the conclusion either-absurdly - that even if service users are not listened to by clinicians, they do not deserve better; or that epistemic (specifically testimonial) injustice is the wrong concept with which to theorise what service users mean when they complain they are 'not listened to' (etc).

The strength of the connection between mental illness and rationality impairments has of course been questioned. Almost everyone suffers lapses of rationality, and there is evidence that people make decisions, including those about their healthcare, less rationally and in a less considered way than some constructions of autonomy and decision-making assume. ${ }^{21}$

But let us assume that the connection holds. Even so, the 'swift argument' would be too swift. Of crucial importance here is the fact that the impairments to rationality associated with mental illness vary depending on the illness. Some are continuous impairments: think of people who suffer long-term depression and so underestimate their own talents or attractiveness, or regularly overreact to minor setbacks; or sufferers from obsessive compulsive disorder who wash their hands many times a day despite knowing that they have already got rid of all the germs. Some impairments to rationality, by contrast, are episodic: delusions in schizophrenia, or the impairments associated with bipolar disorder. So reliably inferring that someone's rationality is impaired now because they have some mental health condition will depend very much on the nature of the condition. Moreover, for standing and episodic conditions alike, impairments to rationality are-usually-domain specific. ${ }^{16 i}$ Thus even mid-episode, a person experiencing psychosis may be not just accidentally knowledgeable but wholly reliable with respect to their name and address, the weather, their likes and dislikes, and their religious beliefs (if any), and the same is true of sufferers from non-episodic conditions. We will return to this issue but for now, epistemic injustice cannot be summarily dismissed as a tool in mental health contexts, because rationality-this 'capacity essential to human value'-is not all or nothing. In failing to listen to a sufferer from mental health problems, we are stillpotentially-insulting them in respect of that capacity even if they admittedly lack some aspect of it.

\section{Utterances during delusional episodes: undeserved credibility deficits?}

With that clarification in place, let us examine one of the most detailed discussions in the literature to date-Sanati and Kyratsous $^{18}$-on testimonial injustice and mental illness, which argues that service users in a common type of setting are victims of testimonial injustice. I argue that the applicability of the concept-at least on the understanding of it on show in the central race and gender cases-comes

${ }^{\mathrm{i}}$ Thanks to Saara Majid for pressing this point. 
under severe strain, because the issue of whether and how mental illness compromises epistemic powers is not clearly faced.

Sanati and Kyratsous describe two individuals, each an emergency admission with a psychotic presentation. JN 'present[ed] with an acute onset of psychotic phenomena', including delusions, and reported that her partner was being unfaithful to her; the psychiatric team 'formulated [these] ... as a case of delusional jealousy' (p483). ${ }^{18}$ In fact, however, the reports were correct, and non-accidentally so-that is, JN knew, rather than simply imagined and happened to be right, that her partner was being unfaithful. In the second case, MG was 'picked [up] by the police' having threatened to attack someone for abusing a close relative. On admission he 'was found to be acutely psychotic'; refusing treatment, he was 'detained under the Mental Health Act' (p482). ${ }^{18}$ His accusations against the alleged abuser were assumed to be 'part of an extended delusional system', but turned out to be 'factually true'. By this we take it that the authors do not mean accidentally true (ie, that MG delusionally believed that someone was abusing his relative, and coincidentally this was the case), but that MG knew it: 'there was (as it later transpired) nothing delusional to [MG's] reaction to the abuse' (p483). ${ }^{18}$ Crichton et al describe a similar case, where a 'young man on an acute psychiatric ward [in Munich] ... said he was a relative of the then Soviet leader'. He was (so he presumably knew it), but the consultant assumed this was 'a grandiose delusion' (p66). ${ }^{15}$

Neither JN's nor MG's testimony is treated as credible by the hospital psychiatric team. Furthermore, what they said was both true and (as far as one can tell) the expression of knowledge. But, as Alan's case (above) shows, that is not sufficient for epistemic injustice. Did they satisfy Fricker's further conditions?

Sanati and Kyratsous emphasise that although delusions are epistemically irrational (eg, involve impairments to the sufferer's ability to 'stay in touch with reality'), not all epistemic irrationality is a case of delusion-even in a delusional patient (p480). ${ }^{18}$ They also observe that there is no consensus on how to distinguish delusions from other forms of epistemic irrationality, for example, self-deception (p480) ${ }^{18}$ However, it is not clear how any of this makes a difference with JN and MG. With respect to the particular issues of the partner's infidelity and the allegation of abuse against a relative, JN and MG were not just suffering from some non-delusional form of epistemic irrationality: they were not epistemically irrational at all.

Sanati and Kyratsous also point out that prejudice is 'attached to the label of mental disorder', and not just in the case of service users with psychosis (p483; cp. 15, 13). ${ }^{18}$ However, arguably the psychiatric team's assessment of JN's and MG's epistemic powers are not owed to the fact that they bore a label, as it might be if the team had been assessing simply on the basis of the service users' medical history (eg, when seeing them for a follow-up appointment): the assessments were made on the basis of presentations which the team saw first-hand. Given that fact, the team's view that-the particular case of her partner apart- JN was epistemically irrational (whether in the form of delusions or otherwise) looks well grounded. So were the team correct to regard JN's testimony specifically about her partner as incredible? One might appeal, by way of objection, to the point that rationality is domain specific and indeed, the psychiatric team took JN at her word when (for example) she gave her name. More complicatedly, one might expect the non-delusional parts of a longer delusional narrative to be distinguished by, for example, difference in tone of voice, non-repetitiveness, nonstandardized content as compared to the rest of the narrative, or ability to give relevant further details when asked. ${ }^{\mathrm{ii}}$ But Sanati and Kyratsous do not mention such marks, so let us assume for argument's sake that they were absent. Nor are different 'domains' always easy to distinguish: perhaps JN's partner's behaviour was not salient to the psychiatric team as a domain in which her epistemic capacities were distinctively unimpaired. If either of these things was so-no variation in detail, and so on, across different parts of the narrative, and no salience of the partner's behaviour as a distinct domain - then presenting as delusional is arguably a good heuristic for being incredible across all components of that narrative (though not about other things said on admission, for example one's name). Thus, in the same way, Alan's friend (above) would be justified in disbelieving Alan's (knowledgeable) diagnosis of her medical condition, though JN is disbelieved, it is a case of 'innocent error'1 (p22) not a credibility deficit. And even if she did suffer a credibility deficit, the prejudice necessary for the credibility deficit to count as testimonial injustice has yet to be identified.

Again, we are told that 'in further examination' MG's belief about abuse turned out to be true. Does that mean further questioning of MG himself, or further investigation of another sort? If the former, then there may have been culpable epistemic error-for example, not attending to tone of voice or relevant detail. But inattention need not be caused by prejudice and testimonial injustice, for Fricker, requires prejudice, and the fact that the team investigated further and then changed their view speaks against the presence of prejudice. The grounds Sanati and Kyratsous give for saying testimonial injustice occurred in these two cases are therefore insufficient. Obviously, the analysis of two cases of the emergency admission of adults suffering from delusions does not show testimonial injustice could not occur in cases of this kind but, if it does, the onus is on others to demonstrate it.

\section{Epistemic (testimonial) injustice: lessons from children's and young people's experiences}

The fact that the concept of epistemic injustice has been applied too freely by Sanati and Kyratsous does not, however, show that it cannot be applied in cases of mental health problems: far from it.

I now step sideways and focus on children and young people (CYPs) with health problems, including mental health problems. ${ }^{\text {iii }}$ $\mathrm{Day}^{22}$ (p4) suggests CYPs' competence to engage in healthcare decisions is often called into question. CYPs' statements about a wide range of facts about themselves-their own physical state, symptoms, wants and best interests-tend to be discounted in clinical settings on the grounds that, because they are CYPs, they are unreliable, poor judges of their own interests, their wishes are volatile and unstable and so on, and this may be doubly so in the case of CYPs diagnosed with a mental illness ${ }^{23}$ (p213). Being a CYP is treated as a heuristic for epistemic unreliability across a wide range of domains.

However, while Alderson ${ }^{24}$ (p206) concedes that 'children's knowledge, judgement, foresight, freedom of choice, control and agency are all very limited' so too, she continues, are adults' capacities. Moreover recent explorations of CYPs' competence have demonstrated they are capable of more than previously

\footnotetext{
ii Thanks to a contributor to an Oxford MSt in Practical Ethics seminar for emphasising this point.

${ }^{i i i}$ I focus on children's health (including mental health) decisions because data have been carefully gathered for this case. But any data about children and decision-making, or children as witnesses about their own condition, would be relevant.
} 
thought possible, demonstrating a 'fault line between their moral competence in practice, and their ascribed low moral status, 25 (p2010).

Wiesemann ${ }^{26}$ among others has emphasised that CYPs, and not only older ones, have much in common with adults with respect to the stability of their preferences, their capacity to make realistic assessments of risk, to take responsibility in their own care $^{27}$ (p33), and to contribute informed opinions about their own health regimes and practices. ${ }^{28}$ Even children as young as 4 with type 1 diabetes have shown that they can be informed, responsible and reliable in some care decisions. ${ }^{27}$ Again, CYPs can provide balanced information about the mental health services they received, including on the therapeutic process and techniques $^{29}$ (p27).

There may be scepticism as to whether all the types of issue referred to are about CYPs' credibility, and so candidates for treatment in terms of testimonial injustice (though cp.17, who sees all issues to do with capacity as epistemic). But such scepticism lacks force. Suppose a clinician disregards a CYP's statement about their treatment preferences. The sceptic might argue that though one could treat this as an epistemic issue-people can lack self-knowledge with respect to what they want-the case is more likely to be one where a clinician says 'I believe you when you say you want $\mathrm{x}$, but $\mathrm{x}$ is not what is best for you'. So the issue isn't whether the CYP is credible about what they want, but who thinks they know what's best for the CYP. Or consider the question whether the CYP can take responsibility for their own care: again, the issue could be how reliably the CYP can predict their own future behaviour, and therefore about their credibility. But, argues the sceptic, it is more naturally interpreted as a question about trusting the CYP to stick to their good intentions. So, whatever else they may be doing wrong, the clinician in either case is not inflicting a distinctively testimonial injustice.

In reply, one could construe a CYP's (or anyone's) claims about what they want (etc.) as claims about the state of their own mind. However, such claims do not have to be construed this way as a condition of the clinician-CYP disagreement being a disagreement about credibility. A person's claims about what they want are, ordinarily, answerable to evidence about what's good, not to psychological evidence about themselves. ${ }^{30}$ So in discounting the CYP's claims on the grounds that $\mathrm{x}$ is not best for the CYP, the clinician is precisely discounting the CYP as a source of knowledge on what they want. Since the CYP's credibility is at issue, the possibility of testimonial injustice remains in play. Similar points could be made about responsibility.

Thus it's not just that there are things CYPs happen to know and about which they are disbelieved. It is rather that there are whole domains on which they are potentially reliable informants about themselves, and about which they are disbelieved. This, in Fricker's terms, is enough to establish that CYPs are liable to suffer a credibility deficit in clinical settings. Not that all CYPs suffer credibility deficits: some may be deservedly believed and others deservedly disbelieved. But it's enough for my purposes that credibility deficits are commonly suffered by CYPs in clinical contexts: there is no need to show that they invariably are.

\section{CYPs and credibility deficits: ignorance or prejudice?}

But-recalling Fricker's condition (2) above for epistemic injustice-are these credibility deficits the result of prejudice?

Ignorance appears different from prejudice: the concept of ignorance is neutral as to its cause, whereas prejudice sounds like a cause-maybe a distinctive kind of cause-of ignorance, or perhaps a cause of the persistence of ignorance despite good contrary evidence. But now, is being a CYP manifestly irrelevant to someone's capacity to know about the benefits (for them) of a given treatment option (say), so that if one disbelieves the CYP's testimony, prejudice is presumptively at work? To be sure, Kant is just one of a long queue of people to say-questionably-that CYPs by nature lack the capacity 'to employ their understanding without the guidance of another, ${ }^{31}$ and this view is widespread also in modern times ${ }^{32}$; see also Refs. 26 33. The problem is that research (including some of the research cited here) to the effect that CYPs are credible about treatment options (etc) seems to tell us things about CYPs' capacities that were not obvious before. But if we really are emerging from a period of ignorance thanks to new knowledge becoming available, the challenge is that credibility deficits now suffered by CYPs are the result of ignorance, not prejudice. ${ }^{\text {iv }}$ And so, if prejudice is a necessary condition for epistemic injustice, CYPs would not suffer epistemic injusticean unpalatable conclusion.

Replying to this challenge, if ignorance really is at issue, one might expect the research cited on CYPs' knowledgeability to be surprising to the non-clinical public but well-known to clinicians at the coal-face of clinical encounters with CYPs: it takes time for specialist knowledge to travel. But clinicians (although presumably not all of them), who have the greatest opportunity to encounter CYPs as knowledgeable, seemingly do not reliably treat them as such. For example, CYPs' complicated consent may be mistaken for mere compliance, or reasoned refusal seen as childish resistance. ${ }^{27}$ Decisions that adults perceive as undesirable are often constructed as incompetent ${ }^{34}$ (p513) even where they are not; to 'prove' their capacity, CYPs need to concur with clinical advice to demonstrate they can make 'rational', 'competent' decisions $^{35}$ (p102)-even if they wish to reject the advice. That is, it looks as if the possibility that CYPs both are competent and diverge in their views from clinicians is ruled out from the start. Again, if it seems as if CYPs are less knowledgeable than they are, that is arguably because adults fail to share relevant information, ${ }^{33}$ or use complicated medical language, ${ }^{36}$ or fail to understand the different ways children express themselves. ${ }^{37}$ So, since clinicians have an interest in making well-informed decisions, why don't they more often frame their questions in terms CYPs understand? The answer again seems to be the assumption that CYPs would have nothing to contribute even if they did understand the questions. CYPs' utterances are not seen as (potential) evidence of their state of knowledge, but rather reinterpreted against a background assumption that they are not knowledgeable. Because it is thus evidence-proof, the assumption that they aren't knowledgeable-more precisely, that they are only knowledgeable if they concur with the clinician, so are not independent sources of knowledge-bears the hallmarks of prejudice.

\section{Is prejudice necessary for testimonial injustice?}

Let us assume therefore that CYPs often suffer credibility deficits as a result of prejudice, not ignorance. Still, should we follow Fricker in treating prejudice as a necessary condition of epistemic injustice? Some writers on epistemic injustice deploy the notion of 'identity prejudice': epistemic injustice occurs when a 'negative identity-prejudicial stereotype"1 (p35) undermines credibility. But that is questionable. Suppose Diana's teacher always dismisses Diana's contributions to class, whether they are knowledgeable or not, while other students

\footnotetext{
${ }^{\text {iv }}$ Or at least it would be too early to tell whether they are: the answer would depend on whether or not clinicians' attitudes changed as more research of the kind we cite is published, taught in medical schools and so on.
} 
who make similar contributions are praised. That sounds like injustice. But it's surely possible that the teacher dislikes Diana personally, not on account of any group identity of Diana's. The conclusion which creates minimal disturbance to Fricker's view is that the injustice here is epistemic, epistemic injustice requires prejudice but prejudice does not always depend on negative stereotyping.

But now consider the case where a CYP with type 1 diabetes tells a clinician about the effectiveness of their treatment regime, and is ignored. Again, it seems crystal clear that an injustice is being committed-what reason could there be for that person not to be listened to on that subject? (This opens up the space for a discussion of 'expertise by experience', ${ }^{38-40}$ which I cannot go into here.) But while an identity prejudice against CYPs as such might be operative here, I suggest that a hostile attitude towards the speaker, whether based on stereotyping or not is, pace Fricker, not necessary for testimonial injustice: epistemic arrogance on the part of the hearer, including arrogance associated with expert (including clinical) roles ${ }^{19} 41$ (p25), is sufficient independently of any particular con-attitude from the hearer towards the would-be giver of testimony.

Thus even if the conditions on prejudice are weakened so as not to involve stereotyping, if testimonial injustice requires the operation of prejudice, some CYPs whose knowledgeable testimony is undeservedly ignored by experts will not count as suffering testimonial injustice. But since they clearly suffer injustice of some kind, a potentially useful concept runs out of steam sooner than it needs to. I conclude that prejudice does not deserve the exclusive position within the concept of testimonial injustice that it has on Fricker's account. Instead, it should be seen as a species of a broader genus, of which expert arrogance is another-and there may be others. This adjustment gets a more intuitive result with some CYPs' cases I've been discussing, and preserves the applicability of the concept.

\section{Delusions again, and the gap between being listened to and being believed}

I have argued that discounting CYPs' testimony in clinical settings is often a case of epistemic (testimonial) injustice, and the more frequently so if the conditions for applying the concept are weakened as proposed. I do not have the data to make a similar case for epistemic injustice in the context of adult mental health services. But I suspect similar data is not hard to find, ${ }^{4}$ for example, with respect to service users' views on the efficacy of treatment options, or on the higher standards of rationality service users are expected to meet to be taken seriously. Consequently, the concept of epistemic injustice has great potential in the case of adult mental health service users: the experiences of CYPs point the way. ${ }^{v}$

But if that is correct, why do Sanati and Kyratsous focus on such a doubtful case of putative epistemic injustice-where clinicians disbelieve claims made in the midst of a delusional episode? The principle of charity suggests an explanation is needed. Providing one takes us to the vexed topic of the epistemic status of delusions, and to the limitations of the concept of testimonial injustice in accounting philosophically for the importance of being listened to in psychiatric contexts.

I have encountered the view that philosophy can help service user campaigns for recognition by challenging the idea that there

vee also Ref. 49 for helpful evidence from an adult nonpsychiatric service-user group. is a 'single reality', because if there isn't, it is left open for delusions-however different from mainstream views of the worldto express knowledge. This thought may be detected $\mathrm{in}^{42}$ :

We shouldn't be colluding with the idea that there is only one way to interpret reality, one set of beliefs which are acceptable, and another that are 'delusional'. Instead we should be accepting and promoting the right of people to be different. ${ }^{42-44}$

If that thought is right, it follows that in doubting the credibility of mid-delusion utterances clinicians may be rejecting the knowledgeability of non-mainstream worldviews, and so inflicting epistemic injustice. That such a metaphysical question should be focused on the knowledgeability or otherwise of service user utterances mid-episode reflects, I suggest, a combination of two factors. First, delusional presentations are one of the most ethically sensitive contexts in psychiatry, partly because it is a context in which psychiatrists can detain service users involuntarily $^{45}$ (p265ff). So, as the concept of epistemic injustice gains ground as a tool in campaigns for service user recognition, there is intellectual pressure to reinterpret the putative ethical harms suffered by service users in the context of delusional presentations as epistemic injustices. So if the ethical risk is that of inflicting epistemic injustice, then-the thought runs-treating service users justly must require believing their delusional utterances. I suggest that Sanati and Kyratsous are reacting to this pressure. If they are not, it is hard to understand why they work so hard to demonstrate that service users suffer epistemic injustice in their unpromising pair of cases, when the literature on CYPs suggests there is a much more fruitful range of psychiatric cases where epistemic injustice would be easy to show.

However, this thought involves a confusion-never mind whether a clinician could believe something just because it would be unjust not to. Delusions, though sometimes accidentally true, are surely not knowledgeable. Admittedly, clinicians sometimes say that delusions are 'true for the service user', so let's suppose this is an awkward way of saying the service user knows how things feel or seem to him or her: so when the service user says 'my husband is being unfaithful', ${ }^{18}$ 'they wanted to kill [me] and sell [my] organs... to restaurants where cannibals go, ${ }^{46}$ what they mean is not a false claim about the world, but 'It seems to me as if they wanted to kill me...' etc, that is, a true claim about their own state of mind. So interpreted, delusional utterances would give rise to no credibility problem.

But to take service users mid-delusion merely as making accurate reports about their states of mind misses the point. Clinicians would be irresponsible not to take an interest in what service users know or do not know about their surroundings (their husband's behaviour, the restaurants, etc). It is not just that a diagnostically important concept such as 'delusion' would otherwise be impossible to apply: if people really are trying to kill (etc) the service user, the clinician needs to react appropriately. Clinicians have to understand delusional claims as, at least in part, about what they appear to be about, that is, states of the world.

At the same time, to treat delusional claims solely as mistaken claims about the world misses the point in a different way. Zangrilli et $a l^{46}$ are helpful here: 'In the first encounter', they say, 'psychiatrists are required to respond to the presentation of delusions so that patients feel understood and respected and that further treatment is facilitated', and 'questioning the patients' beliefs can lead to disagreement which might hinder establishing a positive therapeutic relationship ${ }^{36}(\mathrm{p} 1,2)$. But refraining from questioning is not the same as believing: a confrontation about the truth of the service user's claims is counterproductive, but there are many ways to avoid 
this without endorsing their claims. ${ }^{\mathrm{vi}}$ It is possible to listen to service users in mid-delusion, or to treat their utterances attentively and respectfully, without treating their delusions as knowledgeable about the world. Sometimes service users are helped by basic facts about the clinical encounter, for example, when a nurse made 'arrangements so that we would not be disturbed. She would switch off her bleeper and take her phone off the hook, and sometimes, as there were people outside her room, she would close the blinds. .... She would sit to one side of me instead of across a desk ${ }^{47}$ (p104). But there is much more to attentive and respectful listening. In relation to hearing voices, service users want clinicians to take an interest in 'who or what the voices represent, and what problems the voices represent', to see them 'as a meaningful and interpretable response to social, emotional and/or interpersonal circumstances'. ${ }^{48}$ Another service user is grateful that the clinician 'wanted to get to know the voices I was hearing' and 'rather than telling me that the beliefs I had were mere delusions ... he focused on how these beliefs made me feel $^{47}$ (p107).

Attentive and respectful listening, therefore, need involve neither—per impossibile—believing delusional utterances construed as about the world, nor believing them by reducing what the service user is trying to communicate to simplistic claims about how the world seems. Certainly service users mid-delusion deserve to be listened to. But that—and this is the crucial point—is because being listened to in this context, unlike the context of the witness-box, does not primarily consist in being believed. But the concept of epistemic (testimonial) injustice only really has application where the goal of service user (or anyone's) utterance is to be believed. Consequently, while there are surely many cases where adult service users suffer testimonial injustice, cases of service user utterance mid-delusionunlike service user testimony on the efficacy of a drug treatmentsuggest that epistemic (specifically, testimonial) (in)justice is not always the right conceptual tool with which to theorise the entitlement to be listened to.

This takes us back to the earlier 'swift objection' to Fricker (sec. 3) - that in so far as they are irrational, sufferers from mental illness do not meet the rationality threshold for entitlement to epistemic justice. My initial reply to that relied on the observation that rationality and its impairments are domain specific. However, that reply does not apply to claims that are part of the content of a delusional episode. Now, if epistemic (testimonial) injustice provides the only theoretical interpretation of the service user entitlement to be listened to, we have a choice between three equally unattractive options: either (1) in their mid-delusion utterances service users do no more than report on their own present state of mind, so their claims are (uninterestingly) credible, so they are treated epistemically justly, so they receive all the listening to which they are entitled; or (2) since service users need to be listened to, they need epistemic justice, so their delusional claims need to be believed; or (3) because delusional claims are incredible, service users do not meet the first condition for suffering epistemic injustice, so to the extent that they are not listened to, this is at is should be.

Nothing I have said makes me want to go back on the view that mental health service users are sometimes not listened to (which is excluded by (1)); or on the view that they are entitled to be listened to, to be treated as persons and so on, and that they are so entitled even when their epistemic powers are impaired, for example,

\footnotetext{
${ }^{\mathrm{vi}}$ I take it that this, rather than any metaphysical thesis about realism, is what Knight ${ }^{42}$ means by 'accepting a person's belief system doesn't mean you have to personally share it, or even pretend to share it. Rather it is about respecting another person's reality ... and helping that person to cope with their experiences'.
}

mid-delusional episode (which is excluded by (3)). Meanwhile (2) leaves service users who wish, rightly, to assert their entitlement to be listened to with an impossible metaphysical mountain to climb. But, to repeat: there is more to being listened to than being believed. So epistemic (in)justice cannot be the only conceptual tool with which to theorise the entitlement to be listened to in psychiatric contexts. Given the imperative to listen to service users, I conclude that it is just as well that it is not.

\section{CONCLUSIONS}

Epistemic (testimonial) injustice, according to Fricker, has two built-in necessary conditions: to suffer such injustice, one must (1) suffer an undeserved credibility deficit, and (2) do so as a result of prejudice. The existing literature on epistemic (testimonial) injustice in psychiatric contexts, which has tended to focus on service user utterance middelusion, has not done well at showing that service users even satisfy condition (1), but this does not show they don't. And indeed, attention to the case of CYPs reveals this group of service users at least do often satisfy (1). They also clearly sometimes satisfy condition (2), that is, when they are undeservedly disbelieved it is sometimes as a result of prejudice (rather than as a result of mere ignorance of CYPs' epistemic capacities). When they are undeservedly disbelieved, is it always as a result of prejudice? Liberalising the concept of prejudice so it does not require stereotyping helps in this direction. But even then, there seem to be cases where service users are unjustly disbelieved without being victims of prejudice. To preserve the idea that the injustice suffered is testimonial, therefore, Fricker's condition (2) should not be seen as necessary, but as one of two or more alternative necessary conditions.

As so far summarised, the aim of the paper has been to loosen Fricker's necessary conditions on the concept of epistemic (testimonial) injustice so as to preserve the applicability of the concept to cases of mental health service users. But the paper also argues that there are limitations to the applicability of the concept, and it is injurious to service user campaigns to make their voices heard not to recognise that there is more to being listened to than being believed, and therefore more to the entitlement to be listened to than the entitlement to epistemic (testimonial) justice.

Given the wealth of examples of epistemic (testimonial) injustice in the CYP cases, it is puzzling why similar examples-for example, of service user testimony on the efficacy of treatments-have not been more energetically gathered in adult cases. I argue that the salience of delusion in campaigns for service user recognition, and the growing popularity of the concept of epistemic injustice as a campaign tool, has led researchers to try to apply the concept of epistemic injustice to adult cases involving delusion. But the concept of epistemic (testimonial) injustice, even liberalised as I propose, fits cases involving delusion badly. Sometimes-as the CYP cases show—being listened to means being believed. But sometimes, as in some delusional episodes, being listened to precisely does not mean that. On pain of bargaining away service users' entitlement to being listened to, we need to make sure the entitlement to being listened to in psychiatric cases is not reduced to the entitlement to epistemic (testimonial) justice. A useful concept in the philosophy of psychiatry risks doing harm if it is not applied with care. ${ }^{\text {vii }}$

\footnotetext{
${ }^{\text {vii }}$ This paper has benefitted immeasurably from collaboration with Kate Martin and from her50, especially in sections 4 and 5 . The conclusions are entirely my own.
} 
Contributors Dr Kate Martin's research contributed to the material on children and mental health, especially in sections 4 and 5.

Funding The authors have not declared a specific grant for this research from any funding agency in the public, commercial or not-for-profit sectors.

Competing interests None declared.

Patient consent for publication Not required.

Provenance and peer review Not commissioned; externally peer reviewed.

Data availability statement There are no data in this work.

ORCID iD

Edward Harcourt http://orcid.org/0000-0002-7176-226X

\section{REFERENCES}

1 Fricker M. Epistemic injustice. Oxford: Oxford University Press, 2007.

2 Medina J. The Epistemology of resistance. Oxford University Press: Oxford, 2013.

3 Potter N. The virtue of Defiance. Oxford University Press: Oxford, 2016.

4 Steslow K. Metaphors in our mouths: the silencing of the psychiatric patient. Hastings Cent Rep 2010:40(4):30-3.

5 Ljungberg A, Denhov A, Topor A. Non-helpful relationships with professionals - a literature review of the perspective of persons with severe mental illness. J Ment Health 2016;25(3):267-77.

6 Laugharne R, Priebe S, McCabe R. Trust, choice and power in mental health care. Int $\mathrm{J}$ Soc Psychiatry 2011;58:496-504.

7 Eriksen Kristin Ådnøy, Arman M, Davidson L, et al. "We are all fellow human beings": mental health workers' perspectives of being in relationships with clients in community-based mental health services. Issues Ment Health Nurs 2013;34(12):883-91.

8 Catty J, White S, Koletsi M, et al. Therapeutic relationships in vocational rehabilitation: predicting good relationships for people with psychosis. Psychiatry Res 2011;187(12):68-73.

9 de Leeuw M, Van Meijel B, Grypdonck M, et al. The quality of the working alliance between chronic psychiatric patients and their case managers: process and outcomes. J Psychiatr Ment Health Nurs 2012;19(1):1-7.

10 McCabe R, Healey PGT. Miscommunication in doctor-patient communication. Top Cogn Sci 2018;10(2):409-24.

11 Priebe S, Richardson M, Cooney M, et al. Does the therapeutic relationship predict outcomes of psychiatric treatment in patients with psychosis? A systematic review. Psychother Psychosom 2011;80(2):70-7.

12 Stringer B, Van Meijel B, De Vree W, et al. User involvement in mental health care: the role of nurses. A literature review. J Psychiatr Ment Health Nurs 2008;15(8):678-83.

13 Thornicroft G, Rose D, Kassam A, et al. Stigma: ignorance, prejudice or discrimination? Br J Psychiatry 2007;190:192-3.

14 Bortolotti L. Overcoming injustice in mental health: is there a role for philosophy? 2018. Available: https://www.nationalelfservice.net/mental-health/overcominginjustice-in-mental-health-is-there-a-role-for-philosophy/

15 Crichton P, Carel H, Kidd IJ. Epistemic injustice in psychiatry. BJPsych Bull 2017:41(2):65-70.

16 Kurs R, Grinshpoon A. Vulnerability of individuals with mental disorders to Epistemic injustice in both clinical and social domains. Ethics Behav 2018;28(4):336-46.

17 Lakeman R. Epistemic injustice and the mental health service user. Int J Ment Health Nurs 2010;19(3):151-3.

18 Sanati A, Kyratsous M. Epistemic injustice in assessment of delusions. J Eval Clin Pract 2015:21(3):479-85

19 Carel H, Kidd IJ. Epistemic injustice in healthcare: a philosophial analysis. Med Health Care Philos 2014;17(4):529-40.

20 Horwitz A, Wakefield J. The loss of sadness. Oxford University Press: Oxford, 2007.

21 Vos IML, Schermer MHN, Bolt ILLE. Recent insights into decision-making and their implications for informed consent. J Med Ethics 2018;44(11):734-8.
22 Day C. Children's and young people's involvement and participation in mental health care. Child Adolesc Ment Health 2008;13(1):2-8.

23 LeFrançois B. 'It's Like Mental Torture': Participation and Mental Health Services. Int J Child Rights 2008;2008(16):211-27.

24 Alderson P. The philosophy of critical realism and childhood studies. Glob Stud Child 2016;6(2):199-210.

25 Mayall B. Towards a sociology for childhood: thinking from children's lives. Maidenhead: Open University Press, 2009.

26 Wiesemann C. Moral equality, bioethics, and the child (Kindle Edition). Switzerland: Springer International Publishing, 2016.

27 Alderson P, Sutcliffe K, Curtis K. Children's competence to consent to medical treatment. Hastings Cent Rep 2006;36(6):25-34

28 Sutcliffe K. Shared decision-making - an evidence-based approach for supporting children, parents and practitioners to manage chronic conditions. London: Institute of Education, 2010

29 Davies J, Wright J. Children's voices: a review of the literature pertinent to Looked-After children's views of mental health services. Child Adolesc Ment Health 2008;13(1):26-31.

30 Authority MR. Estrangement: an essay on self-knowledge. Princeton University Press: Princeton, 2001.

31 Kant INisbet THB, ed. Answer to the Question 'What is Enlightenment? London: Penguin, 2009.

32 Mayall B. A history of the sociology of childhood. London: Institute of Education Press, 2013.

33 Alderson P, Montgomery J. Health care choices: making decisions with children. London: IPPR, 1996.

34 McCabe MA. Involving children and adolescents in medical decision making: developmental and clinical considerations. J Pediatr Psychol 1996:21(4):505-16.

35 Mackenzie R, Watts J. Is childhood a disability? Using Mental Capacity Tribunals and the Deprivation of Liberty Safeguards to shield children's capacity to consent to and refuse medical treatment. Tizard Learning Disability Review 2014;19(2):96-106.

36 Coyne I. Children's participation in consultations and decision-making at health service level: a review of the literature. Int J Nurs Stud 2008;45(11):1682-9.

37 Carral Bielsa V, Braddick F, Jané-Llopis E, et al. Child and adolescent mental health policies, programmes and infrastructures across Europe. Int J Ment Health Promot 2010;12(4):10-26.

38 Basset T, Faulkner A, Repper J. Lived experience leading the way: peer support in mental health, 2011. Available: http://www.together-uk.org/wp-content/uploads/ downloads/2011/11/livedexperiencereport.pdf

39 Department of Health. The expert patient: a new approach to chronic disease management for the 21st century. London: Department of Health, 2001.

40 Repper J, Aldridge B, Gilfoyle S. Peer support workers: theory and practice. ImROC, Centre for Mental Health \& MH Network;NHS Confederation, 2013.

41 Alderson P. Giving Children's Views "Due Weight" in Medical Law. Int J Child Rights 2018;26(1):16-37

42 Knight T. Beyond belief: interview with Dr Tamasin knight. 1. ENUSP Bulletin Newsletter of the European Network of (ex-) Users and Survivors of Psychiatry, 2010.

43 Georgaca E. Reality and discourse. Br J Clin Psychol 2000;73:227-42.

44 Waddingham R. Don't Confront, Don't Collude': Exploring our Beliefs about 'Delusions'. Short Thoughts 2018\#1. Available: https://vimeo.com/88097095

45 Burns T. Our necessary shadow. London: Penguin, 2014

46 Zangrilli A, Ducci G, Bandinelli PL, et al. How do psychiatrists address delusions in firs meetings in acute care? A qualitative study. BMC Psychiatry 2014;14:178.

47 Cooke A. Understanding psychosis and schizophrenia. British Psychological Society, 2017.

48 Corstens $\mathrm{D}$, Longden E, McCarthy-Jones S. Emerging perspectives from the hearing voices movement. Schizophr Bull 2014:40:285-94.

49 Blease C, Carel H, Geraghty K. Epistemic injustice in healthcare encounters: evidence from chronic fatigue syndrome. J Med Ethics 2017;43(8):549-57.

50 Martin K. A critical realist study of shared decision-making in young people's mental health inpatient units. Doctoral thesis (Ph.D), UCL (University College London) 2019 Available: https://discovery.ucl.ac.uk/id/eprint/10071358/ 